\title{
Structure Conformation, Vibrational Properties, NLO Activity, HOMO-LUMO and Thermodynamic Parameters of Dinicotinic Acid Using Experimental and Theoretical
} Approach

\author{
Gaddam Ramesh ${ }^{1(\mathbb{D})}$, Chinnala Venkateshwarlu ${ }^{2(\mathbb{D})}$, Katla Rajashekar ${ }^{3(\mathbb{D})}$, Guguloth Vinod ${ }^{3(\mathbb{D})}$, \\ Banoth. Naresh ${ }^{3}$ (D), Guguloth Harikishan ${ }^{3}$ (D), Jarupula Laxman Naik 1,*(D)

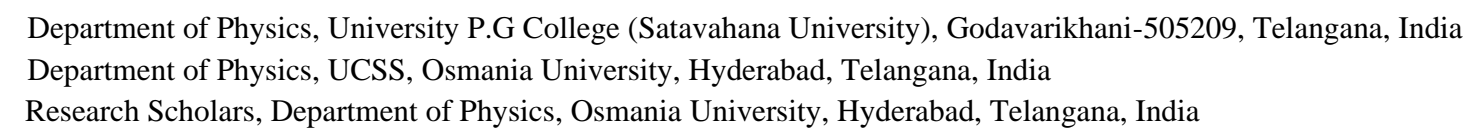

Scopus Author ID56737221500

Received: 30.03.2021; Revised: 15.05.2021; Accepted: 20.05.2021; Published: 8.08.2021

\begin{abstract}
In the present study, the Dinicotinic acid was characterized by FTIR and FT-Raman spectra in the range of 4000-450 and 4000-50 $\mathrm{cm}^{-1}$. The most stable molecular structure and optimized geometrical parameters are calculated using DFT studies. Normal Co-ordinate Analysis (NCA) was studied out by solving Inverse Vibrational Problem using 74-valence force field calculations using overlay least square technique. It reproduces into 35 fundamental frequencies with an rms error of 9.28 $\mathrm{cm}^{-1}$ in the zero-order calculations. Based on PED, vibrational modes are assigned for this molecule. The energy of HOMO \& LUMO, NLO parameters, and thermodynamic parameters were computed.
\end{abstract}

Keywords: 35PDICA; FT-IR; FT-Raman; DFT; NLO properties; HOMO-LUMO.

(C) 2021 by the authors. This article is an open-access article distributed under the terms and conditions of the Creative Commons Attribution (CC BY) license (https://creativecommons.org/licenses/by/4.0/).

\section{Introduction}

Pyridine carboxylic acids are the most important compounds for human beings and are implicated in several biochemical processes. We investigated the structural conformation and molecular vibrational properties of Dinicotinic acid using their experimental IR and Raman spectra; and applied to NCA using DFT of Dinicotinic acid and solving IVP. In our previous paper [1], we have reported the experimental and computational study of some pyridine dicarboxylic acid.

As the same procedure, now we investigated the structure and vibrational properties of dinicotinic (3,5-pyridine di-carboxylic) acid. Dinicotinic acid has more significance in coordination chemistry [2, 3]. In medicines, PDA is found in HIV agents [3-5]. Pyridinedicarboxylic acids have huge applications in the chemical and pharmaceutical fields. Kose et al. [6] reported the FT-IR, FT-Raman, and NMR studies of neutral and anion forms for 3,5pyridine dicarboxylic acid.

The current study intends to have theoretical computations of FT-IR, FT-Raman, and vibrational characteristics using DFT (Density Functional Theory) and NCA (Normal Coordinate Analysis) approach. It is also designed to have the theoretical calculation of 
optimized geometrical parameters, HOMO-LUMO, NLO, and thermodynamic parameters for a chosen molecule using density functional theory (DFT).

\section{Material and Methods}

The title molecule was purchased from Sigma Aldrich Chemical Company without further purification for the spectral measurement. The FTIR spectrum of dinicotinic acid has been recorded in the region $4000-450 \mathrm{~cm}^{-1}$ by Perkin Elmer FT-IR spectrum instrument, and FT-Raman spectra of the chosen molecule have been recorded from the range $4000-50 \mathrm{~cm}^{-1}$.

\subsection{Computational procedure.}

\subsubsection{Geometry optimization.}

The first task is to calculate the most stable conformer for the Pyridine-3,5-dicarboxylic acid (35PDICA). For this, all calculations were done with the Gaussian-09 software package [7]. All the vibrations of 35PDICA were calculated by using B3LYP [8, 9] methods. This molecule gives 8 (eight) conformers for 35PDICA, as depicted in Figure-1. Among all the conformers, Figure-1(d) has minimum global energy for the title molecule. The optimized structure along with energy $E=-625.6009$ Hartree is depicted in Figure-1. The optimized structural parameters of the title molecule are presented in Table 1. In the present study, the bond length between the pyridine ring and the two acid groups is 1.487 and $1.404 \AA$. The average bond distance of C-N (N1-C2 and C6-N1) is computed as $1.334 \AA$ for the title compound.



(a) $C_{1}$ Conformer $\left(E_{1}=-625.5368\right.$ Hartree $) \quad$ (b) $C_{2}$ Conformer $\quad\left(E_{2}=-625.5692\right.$ Hartree $)$


(c) $\mathrm{C}_{3}$ Conformer $\left(\mathrm{E}_{3}=-625.5692\right.$ Hartree $)$

(d) $\mathrm{C}_{4}$ Conformer $\left(\mathrm{E}_{4}=-625.6004\right.$ Hartree $)$

Figure 1. Optimized structure along with energy $(E=-625.6074$ Hartree $)$ of 35PDICA.

Table 1. Bond length, bond angle, and torsional angles of 35PDICA.

\begin{tabular}{c|c|c|c|c|c} 
Bond length & Value (̊) & Bond angle & $\begin{array}{c}\text { Value(in } \\
\text { degree) }\end{array}$ & Torsional angle & Value(in degree) \\
\hline $\mathrm{N}_{1}-\mathrm{C}_{2}$ & 1.334 & $\mathrm{~N}_{1}-\mathrm{C}_{2}-\mathrm{C}_{3}$ & 123.03 & $\mathrm{~N}_{1}-\mathrm{C}_{2}-\mathrm{C}_{3}-\mathrm{C}_{4}$ & 0.0 \\
\hline $\mathrm{C}_{2}-\mathrm{C}_{3}$ & 1.404 & $\mathrm{C}_{2}-\mathrm{C}_{3}-\mathrm{C}_{4}$ & 117.68 & $\mathrm{C}_{2}-\mathrm{C}_{3}-\mathrm{C}_{4}-\mathrm{C}_{5}$ & 0.0 \\
\hline $\mathrm{C}_{3}-\mathrm{C}_{4}$ & 1.397 & $\mathrm{C}_{2}-\mathrm{C}_{3}-\mathrm{C}_{4}$ & 119.46 & $\mathrm{C}_{2}-\mathrm{C}_{3}-\mathrm{C}_{4}-\mathrm{C}_{6}$ & 0.0 \\
\hline $\mathrm{C}_{4}-\mathrm{C}_{5}$ & 1.386 & $\mathrm{C}_{4}-\mathrm{C}_{5}-\mathrm{C}_{6}$ & 118.19 & $\mathrm{C}_{6}-\mathrm{N}_{1}-\mathrm{C}_{2}-\mathrm{C}_{7}$ & 173.87
\end{tabular}




\begin{tabular}{c|c|c|c|c|c} 
Bond length & Value $(\stackrel{\mathbf{A}}{)}$ & Bond angle & $\begin{array}{c}\text { Value(in } \\
\text { degree) }\end{array}$ & Torsional angle & Value(in degree) \\
\hline $\mathrm{C}_{5}-\mathrm{C}_{6}$ & 1.392 & $\mathrm{~N}_{1}-\mathrm{C}_{2}-\mathrm{C}_{7}$ & 113.31 & $\mathrm{~N}_{1}-\mathrm{C}_{2}-\mathrm{C}_{3}-\mathrm{C}_{8}$ & -180.0 \\
\hline $\mathrm{C}_{6}-\mathrm{N}_{1}$ & 1.334 & $\mathrm{C}_{2}-\mathrm{C}_{3}-\mathrm{C}_{8}$ & 125.01 & $\mathrm{C}_{2}-\mathrm{C}_{3}-\mathrm{C}_{4}-\mathrm{H}_{9}$ & 180.0 \\
\hline $\mathrm{C}_{2}-\mathrm{C}_{7}$ & 1.513 & $\mathrm{C}_{3}-\mathrm{C}_{4}-\mathrm{H}_{9}$ & 118.74 & $\mathrm{C}_{3}-\mathrm{C}_{4}-\mathrm{C}_{5}-\mathrm{H}_{10}$ & 180.0 \\
\hline $\mathrm{C}_{3}-\mathrm{C}_{8}$ & 1.491 & $\mathrm{C}_{4}-\mathrm{C}_{5}-\mathrm{H}_{10}$ & 121.21 & $\mathrm{C}_{4}-\mathrm{C}_{5}-\mathrm{C}_{6}-\mathrm{H}_{11}$ & 180.0 \\
\hline $\mathrm{C}_{4}-\mathrm{H}_{9}$ & 1.083 & $\mathrm{C}_{5}-\mathrm{C}_{6}-\mathrm{H}_{11}$ & 120.78 & $\mathrm{~N}_{1}-\mathrm{C}_{2}-\mathrm{C}_{7}-\mathrm{O}_{12}$ & -104.56 \\
\hline $\mathrm{C}_{5}-\mathrm{H}_{10}$ & 1.082 & $\mathrm{C}_{2}-\mathrm{C}_{7}-\mathrm{O}_{12}$ & 123.45 & $\mathrm{~N}_{1}-\mathrm{C}_{2}-\mathrm{C}_{7}-\mathrm{O}_{13}$ & 72.25 \\
\hline $\mathrm{C}_{6}-\mathrm{H}_{11}$ & 1.085 & $\mathrm{C}_{2}-\mathrm{C}_{7}-\mathrm{O}_{13}$ & 112.10 & $\mathrm{C}_{2}-\mathrm{C}_{7}-\mathrm{O}_{13}-\mathrm{H}_{14}$ & -176.43 \\
\hline $\mathrm{C}_{7}-\mathrm{O}_{12}$ & 1.202 & $\mathrm{C}_{7}-\mathrm{O}_{13}-\mathrm{H}_{14}$ & 107.36 & $\mathrm{C}_{2}-\mathrm{C}_{3}-\mathrm{C}_{8}-\mathrm{O}_{15}$ & -162.57 \\
\hline $\mathrm{C}_{7}-\mathrm{O}_{13}$ & 1.343 & $\mathrm{C}_{3}-\mathrm{C}_{8}-\mathrm{O}_{15}$ & 124.05 & $\mathrm{C}_{2}-\mathrm{C}_{3}-\mathrm{C}_{8}-\mathrm{O}_{16}$ & 19.14 \\
\hline $\mathrm{O}_{13}-\mathrm{H}_{14}$ & 0.969 & $\mathrm{C}_{3}-\mathrm{C}_{8}-\mathrm{O}_{16}$ & 112.95 & $\mathrm{C}_{3}-\mathrm{C}_{8}-\mathrm{O}_{16}-\mathrm{H}_{17}$ & -180.00 \\
\hline $\mathrm{C}_{8}-\mathrm{O}_{15}$ & 1.207 & $\mathrm{C}_{8}-\mathrm{O}_{16}-\mathrm{H}_{17}$ & 107.61 & & \\
\hline $\mathrm{C}_{8}-\mathrm{O}_{16}$ & 1.349 & & & & \\
\hline $\mathrm{O}_{16}-\mathrm{H}_{17}$ & 0.968 & & & &
\end{tabular}

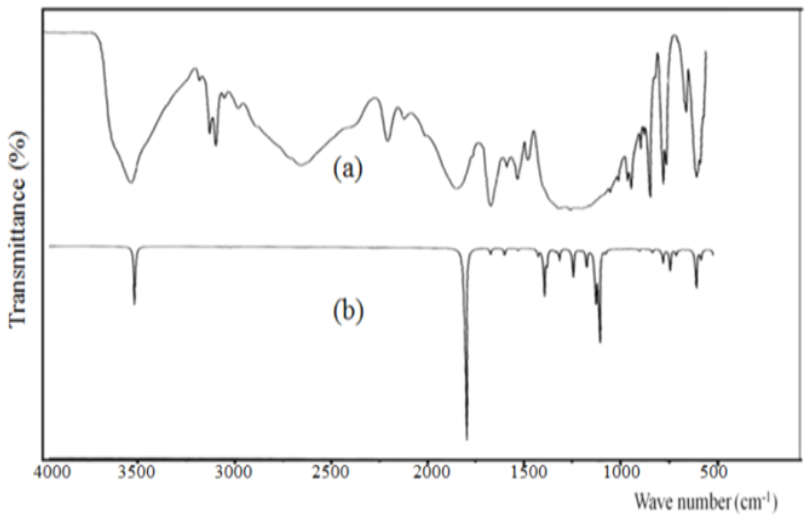

(a)



(b)

Figure 2. (a) Experimental and simulated FTIR of 35PDICA; (b) experimental and simulated FT-Raman spectrum of 35PDICA.

Based on DFT computations, optimized Dinicotinic (3,5-pyridine di-carboxylic) acid has $\mathrm{C}_{1}$ point group symmetry and has 17 atoms with 45 fundamental frequencies. Out of this, thirty-one fundamentals frequencies are in-plane vibrations, and fourteen frequencies are in out-of-plane. All the vibrations of $\mathrm{C}_{1}$ symmetry are active in both IR and Raman.

A detailed description of vibrational modes discussed in our earlier work [1]. Figure 2 represents the calculated and observed FT-IR and FT-Raman spectrum of Dinicotinic acid; all the modes of a given molecule are in Table-2.

2.1.2. Solving inverse vibrational problem (IVP).

Normal coordinate analysis was accepted to solve IVP employing Wilson's GF-matrix method. The geometrical parameters (Table-2) of dinicotinic acid (35PDICA) is calculated by using DFT computations. Thus valence force field was preferred for solving IVP using NCA for all the fundamental vibrations of pyridine-3,5-dicarboxylic acid under investigation. A zero-order NCA of all the fundamental vibrations of 35PDICA was made by IVP [1]. The first set of seventy-four force constants was transferred and thirty-five observed frequencies using Dinicotinic acid with an rms error of $9.28 \mathrm{~cm}^{-1}$. The experimental and theoretically calculated frequencies by Inverse Vibrational Problem (IVP) method \& DFT method are tabulated in Table-2. 


\section{Results and Discussion}

\subsection{Vibrational assignments.}

The vibrational assignments were made by using quantum chemical calculations (DFT) as well as solving the inverse vibrational problem (NCA). Experimental and theoretically (NCA and DFT) calculated frequencies of 35PDICA are shown in Table 2, along with vibrational assignments. The vibrational frequencies are assigned based on PED and eigenvector; obtained based on the computations [10] and based on the suggestions made by Varsanyi for 1,3,5-tri light (35PDICA) substituted benzenes [11], respectively. It is observed that from Table-2, the theoretically calculated frequencies are obtained by using the normal coordinate analysis method are evidence with experimental and DFT values. PED shown in Table-2 is obtained from the results of NCA method.

\subsubsection{Carbon-Carbon (CC) and Carbon-Nitrogen (CN) stretching vibrations.}

The modes $1,8 \mathrm{a}, 8 \mathrm{~b}, 14,19 \mathrm{a}$, and $19 \mathrm{~b}$ are known as $\mathrm{CC} / \mathrm{CN}$ stretching vibrations in pyridine and its derivatives. For the Dinicotinic acid, the modes $8 \mathrm{a}$ and $8 \mathrm{~b}$ are found at 1600 $\mathrm{cm}^{-1}$. The higher frequency has PED to the extent of 50\% from C-C stretching character, and the remaining PED comes from $\mathrm{C}-\mathrm{C}_{\alpha}$ mode $7 \mathrm{~b}$ and ring vibrations in Dinicotinic acid. Hence, the absorptions near $1610 \mathrm{~cm}^{-1}$ are assigned to $\mathrm{C}-\mathrm{N}$ of $8 \mathrm{a}$, and bands near $1591 \mathrm{~cm}^{-1}$ are coming to $\mathrm{C}-\mathrm{C}$ mode $8 \mathrm{~b}$ in P35DICA. CC vibration has PED extent of $36 \%$ combined with $\mathrm{C}-\mathrm{C}_{\alpha}$, whereas the $\mathrm{CC}$ mode to the extent of $58 \%$ mixes with $\mathrm{CH}$ in-plane bending vibration. Hence, $1537 \mathrm{C} \mathrm{cm}^{-1}$ is ascribed to mode $19 \mathrm{a}$, and the absorptions around $1466 \mathrm{~cm}^{-1}$ are assigned to mode $19 \mathrm{~b}$ in pyridine-3,5-dicarboxylic acid, respectively The $\mathrm{C}-\mathrm{C}$ and $\mathrm{C}-\mathrm{N}$ vibrations are concurrences with P. Koczon et al. [12], and C-C vibrations are in good agreement with N. L. John et al. [13].

\subsubsection{Kekule (mode 14) and $\mathrm{CH}$ in-plane bending vibrations.}

C-H in-plane bending vibrations appears around $1000-1300 \mathrm{~cm}^{-1}$ [14-17]. As per density functional theory and the inverse vibrational problem, it is observed at 1266 and $1215 \mathrm{~cm}^{-1}$ in Dinicotinic acid and strong mixing with modes 14 and 3. Kekule and $\mathrm{CH}$ in-plane are presented in Table 2.

Table 2. Detailed vibrational assignments of experimental and theoretical frequencies of Dinicotinic acid.

\begin{tabular}{|c|c|c|c|c|c|c|}
\hline \multirow[t]{3}{*}{ Modes** } & \multicolumn{2}{|c|}{ Obs. freq. } & \multicolumn{3}{|c|}{ Cal. freq. $\left(\mathrm{cm}^{-1}\right)$} & \multirow[t]{3}{*}{ Vibrational assignement } \\
\hline & \multirow{2}{*}{ IR } & \multirow{2}{*}{$\mathbf{R a}$} & \multicolumn{2}{|c|}{ DFT } & \multirow[t]{2}{*}{ NCA } & \\
\hline & & & Uns. & Sc. & & \\
\hline$v(\mathrm{CH}) 2$ & 3090 & 3084 & 3187 & 3087 & 3095 & $2(100)$ \\
\hline$v(\mathrm{CH}) 20 \mathrm{a}$ & - & - & 3140 & 3061 & 3067 & $20 \mathrm{a}(99)$ \\
\hline$v(\mathrm{CH}) 20 \mathrm{~b}$ & 2909 & - & 3008 & 2910 & 2918 & $20 \mathrm{~b}(98)$ \\
\hline$v\left(\mathrm{CC}_{\alpha}\right) 7 \mathrm{~b}$ & - & 1034 & 1059 & 1037 & 1031 & $7 b(40)+19 a(24)+6 a(12)$ \\
\hline$v\left(\mathrm{CC}_{\alpha}\right) 13$ & - & 1305 & 1357 & 1312 & 1310 & $13(43)+19 b(12)+v\left(C_{\alpha}-\mathrm{O}\right)^{\prime}(10)$ \\
\hline$v(\mathrm{CN}) 1$ & 801 & 800 & 824 & 802 & 809 & $1(71)+12(20)$ \\
\hline$v(C C) 8 a$ & 1610 & 1607 & 1630 & 1609 & 1616 & $8 \mathrm{a}(50)+12(19)+7 \mathrm{~b}(12)$ \\
\hline$v(\mathrm{CN}) 8 \mathrm{~b}$ & - & - & 1587 & 1580 & 1591 & $8 b(41)+18 b(28)+14(17)$ \\
\hline$v(\mathrm{CC}) 14$ & 1266 & 1266 & 1281 & 1271 & 1267 & $14(65)+3(34)$ \\
\hline$v(C C) 19 a$ & - & - & 1548 & 1530 & 1537 & $19 a(36)+18 b(24)+7 b(17)$ \\
\hline$v(C C) 19 b$ & 1466 & 1461 & 1497 & 1468 & 1464 & $19 b(58)+18 b(30)$ \\
\hline$\beta(\mathrm{CH}) 3$ & 1215 & - & 1254 & 1218 & 1220 & $3(41)+14(28)$ \\
\hline$\beta(\mathrm{CH}) 18 \mathrm{a}$ & 1055 & - & 1074 & 1056 & 1048 & $18 \mathrm{a}(37)+19 \mathrm{a}(24)$ \\
\hline$\beta(\mathrm{CH}) 18 \mathrm{~b}$ & 1162 & 1149 & 1181 & 1167 & 1150 & $19 b(48)+18 b(30)$ \\
\hline$\beta\left(\mathrm{CC}_{\alpha}\right) 9 \mathrm{a}$ & - & 201 & 180 & 197 & 206 & $9 \mathrm{a}(74)+\tau \tau\left(\mathrm{C}_{\alpha}-\mathrm{O}\right)(12)$ \\
\hline
\end{tabular}




\begin{tabular}{|c|c|c|c|c|c|c|}
\hline \multirow[t]{3}{*}{ Modes** } & \multicolumn{2}{|c|}{ Obs. freq. } & \multicolumn{3}{|c|}{ Cal. freq. $\left(\mathrm{cm}^{-1}\right)$} & \multirow[t]{3}{*}{ Vibrational assignement } \\
\hline & \multirow{2}{*}{ IR } & \multirow[t]{2}{*}{$\mathbf{R a}$} & \multicolumn{2}{|c|}{ DFT } & \multirow[t]{2}{*}{ NCA } & \\
\hline & & & Uns. & Sc. & & \\
\hline$\beta\left(\mathrm{CC}_{\alpha}\right) 15$ & - & 330 & 341 & 329 & 335 & $18 \mathrm{~b}(51)+\tau \tau\left(\mathrm{C}_{\alpha}-\mathrm{O}\right)(33)$ \\
\hline$\beta(\mathrm{CCC}) 6 \mathrm{a}$ & 476 & - & 490 & 469 & 478 & $6 \mathrm{a}(48)+20 \mathrm{a}(25)+\delta\left(\mathrm{C}_{\alpha}=\mathrm{O}\right)(12)$ \\
\hline$\beta(\mathrm{CCC}) 6 \mathrm{~b}$ & 532 & - & 545 & 536 & 530 & $6 \mathrm{~b}(61)+7 \mathrm{~b}(18)+19 \mathrm{a}(14)$ \\
\hline$\beta(\mathrm{CCC}) 12$ & 752 & - & 781 & 754 & 751 & $12(55)+14(15)+7 b(11)$ \\
\hline$\pi(\mathrm{CH}) 5$ & 895 & - & 870 & 891 & 894 & $5(71)+4(22)$ \\
\hline$\pi(\mathrm{CH}) 11$ & 695 & - & 674 & 689 & 698 & $11(100)$ \\
\hline$\pi(\mathrm{CH}) 17 \mathrm{a}$ & 942 & - & 961 & 937 & 947 & $17 \mathrm{a}(98)$ \\
\hline$\pi\left(\mathrm{CC}_{\alpha}\right) 10 \mathrm{~b}$ & - & 189 & 201 & 187 & 180 & $10 \mathrm{~b}(34)+\tau(\mathrm{OH})(15)+4(12)$ \\
\hline$\pi\left(\mathrm{CC}_{\alpha}\right) 17 \mathrm{~b}$ & - & 137 & 140 & 141 & 138 & $17 \mathrm{~b}(49)+4(21)+17 \mathrm{a}(15)$ \\
\hline$\tau(\operatorname{cccc}) 4$ & - & 677 & 681 & 674 & 678 & $5(51)+4(35)$ \\
\hline$\tau(\operatorname{cccc}) 16 \mathrm{a}$ & 496 & - & 501 & 495 & 491 & $\tau\left(\mathrm{C}_{\alpha}=\mathrm{O}\right)(44)+16 \mathrm{a}(24)+10 \mathrm{~b}(18)$ \\
\hline$\tau(\mathrm{cccc}) 16 \mathrm{~b}$ & - & 277 & 301 & 284 & 279 & $16 b(68)+17 b(21)$ \\
\hline$v\left(\mathrm{C}_{\alpha}=\mathrm{O}\right)_{1}$ & 1719 & 1718 & 1740 & 1721 & 1722 & $v\left(\mathrm{C}_{\alpha}=\mathrm{O}\right)(90)$ \\
\hline$v\left(\mathrm{C}_{\alpha}=\mathrm{O}\right)_{2}$ & 1719 & 1718 & 1754 & 1718 & 1729 & $v\left(\mathrm{C}_{\alpha}=\mathrm{O}\right)^{\prime}(91)$ \\
\hline$v\left(\mathrm{C}_{\alpha}-\mathrm{O}\right)_{1}$ & 1368 & - & 1345 & 1371 & 1369 & $18 b(39)+v\left(C_{a}-O\right)(24)+19 b(20)$ \\
\hline$v\left(\mathrm{C}_{\alpha}-\mathrm{O}\right)_{2}$ & 1368 & - & 1349 & 1369 & 1359 & $18 \mathrm{a}(32)+v\left(\mathrm{C}_{\alpha}-\mathrm{O}\right)^{\prime}(21)+1(19)$ \\
\hline$\delta(\mathrm{OH})_{1}$ & - & 1389 & 1391 & 1388 & 1381 & $\delta(\mathrm{OH})(77)+18 \mathrm{a}(20)$ \\
\hline$\delta(\mathrm{OH})_{2}$ & - & 1389 & 1390 & 1384 & 1382 & $\delta(\mathrm{OH})^{\prime}(71)+v\left(\mathrm{C}_{\alpha}=\mathrm{O}\right)^{\prime}(14)$ \\
\hline$v(\mathrm{OH})_{1}$ & 3436 & - & 3624 & 3439 & 3442 & $v(\mathrm{OH})(98)$ \\
\hline$v(\mathrm{OH})_{2}$ & 3436 & - & 3624 & 3441 & 3439 & $v(\mathrm{OH})^{\prime}(99)$ \\
\hline$\delta\left(\mathrm{C}_{\alpha}=\mathrm{O}\right)_{1}$ & 626 & - & 651 & 630 & 634 & $\delta\left(\mathrm{C}_{\alpha}=\mathrm{O}\right)(41)+v(\mathrm{C} \alpha-\mathrm{O})(14)$ \\
\hline$\delta\left(\mathrm{C}_{\alpha}=\mathrm{O}\right)_{2}$ & 626 & - & 652 & 634 & 628 & $\delta\left(\mathrm{C}_{\alpha}=\mathrm{O}\right)^{\prime}(40)+v(\mathrm{C} \alpha-\mathrm{O})^{\prime}(18)$ \\
\hline$\gamma\left(\mathrm{C}_{\alpha}-\mathrm{O}\right)_{1}$ & - & 505 & 497 & 498 & 497 & $\gamma\left(\mathrm{C}_{\alpha}-\mathrm{O}\right)(38)+9 \mathrm{a}(22)+8 \mathrm{a}(14)$ \\
\hline$\gamma\left(\mathrm{C}_{\alpha}-\mathrm{O}\right)_{2}$ & - & 505 & 498 & 501 & 500 & $\gamma\left(\mathrm{C}_{\alpha}-\mathrm{O}\right)^{\prime}(49)+20 \mathrm{a}(20)+8 \mathrm{~b}(11)$ \\
\hline$\tau\left(\mathrm{CC}_{\alpha}\right)_{1}$ & & 81 & 120 & 92 & 89 & $\tau\left(\mathrm{CC}_{\alpha}\right)(39)+10 \mathrm{~b}(21)+\omega(\mathrm{OH} 4$ \\
\hline$\tau\left(\mathrm{CC}_{\alpha}\right)_{2}$ & & 110 & 162 & 109 & 111 & $\tau\left(\mathrm{CC}_{a}\right)^{\prime}(81)+16 \mathrm{~b}(12)$ \\
\hline$\omega(\mathrm{OH})_{1}$ & & & 480 & 471 & 468 & $\omega(\mathrm{OH})(55)+\tau\left(\mathrm{CC}_{\alpha}\right)(23)$ \\
\hline$\omega(\mathrm{OH})_{2}$ & & & 459 & 460 & 468 & $\omega(\mathrm{OH})^{\prime}(44)+17 \mathrm{a}(31)+5(17)$ \\
\hline$\omega\left(\mathrm{C}_{\alpha}=\mathrm{O}\right)_{1}$ & & 798 & 888 & 864 & 862 & $\omega\left(\mathrm{C}_{\alpha}=\mathrm{O}\right)(69)+\tau\left(\mathrm{CC}_{\alpha}\right)(15)$ \\
\hline$\omega_{2}\left(\mathrm{C}_{\alpha}=\mathrm{O}\right)_{2}$ & & 798 & 891 & 871 & 869 & $\omega\left(\mathrm{C}_{\alpha}=\mathrm{O}\right)^{\prime}(70)+10 b(11)$ \\
\hline
\end{tabular}

\subsection{3. $\mathrm{C}-\mathrm{C}_{\alpha}$ vibrations.}

Modes $7 \mathrm{~b}$ and $20 \mathrm{a}$ in dinicotinic acid allocate the two $\mathrm{C}-\mathrm{C}_{\alpha}$ (stretching vibrations), whereas the modes 9a and 15 (in-plane bending vibrations). The two out-of-plane bending vibrations are designated as modes $10 \mathrm{~b}$ and $17 \mathrm{a}$ in Dinicotinic acid. The pair of frequencies near $1034 \mathrm{R}$ and $1305 \mathrm{R}$ are ascribed to $\mathrm{C}-\mathrm{C}_{\alpha}$ stretching vibrations in 35PDICA. All the $\mathrm{C}$ $\mathrm{C}_{\alpha}$ vibrations (i/p and o/p) were shown in Table-2.

\subsection{4. $\beta(\mathrm{CCC})$ vibrations.}

According to NCA, the $330 \mathrm{R}$ and $476 \mathrm{~cm}^{-1}$ are attributed to $6 \mathrm{a}$ and $6 \mathrm{~b}$ vibrational modes, whereas the IR near $752 \mathrm{~cm}^{-1}$ is assigned to mode 12 .

\subsubsection{Ring torsions $\tau(\mathrm{cccc})$ vibrations.}

Ring torsions are designated with modes $4,16 \mathrm{a}$, and $16 \mathrm{~b}$ in pyridine dicarboxylic acid. The absorption near $695 \mathrm{~cm}^{-1}$ is assigned as mode 4 , and this mode has $35 \%$ PED from ring torsion and mixed with $\mathrm{C}-\mathrm{H}$ wagging in the present molecule.

The frequency near $469 \mathrm{~cm}^{-1}$ having $68 \%$ PED from ring torsion character is attributed mode $16 \mathrm{~b}$, whereas the IR absorption near $677 \mathrm{R} \mathrm{cm}^{-1}$ with $34 \%$ PED from $\tau(\mathrm{cccc})$ is assigned mode $16 \mathrm{a}$. 
3.1.6. Vibrations of the acid groups.

The Vibrational assignments of carboxylic acid groups are shown in Table 2, and they are good agreements with K. McCan and J. Laane[18] and Kourat et al. [19]

\subsection{NLO parameters.}

Non-linear optical crystals are considered to be useful future material for applications in many fields [20,21]. NLO behavior has been investigated on various organic, inorganic, and organometallic compounds [22]. NLO effect arises due to the interaction of electromagnetic radiation with the material; as a result, the propagation properties like frequency, phase, and amplitude can changes $[23,24]$. The present research reveals that the organic NLO materials are designed to develop a relatively low-power laser-driven non-linear optical system [25].

The NLO properties [26-29] of dinicotinic acid have been calculated by the DFT computations of first-order hyperpolarizability, electric dipole moment, and total polarizability, and these are furnished in Table 3.

Table 3. First order hyperpolarizability (in $10^{-30} \mathrm{~cm}^{5} / \mathrm{e} . \mathrm{s} . \mathrm{u}$ ), dipole moment and polarizability

\begin{tabular}{l|l|l|l}
$\begin{array}{l}\text { Type of } \\
\text { component }\end{array}$ & $\begin{array}{l}\text { Value with } \\
\text { B3LYP/6-311++G (d,p) }\end{array}$ & $\begin{array}{l}\text { Type of } \\
\text { component }\end{array}$ & $\begin{array}{l}\text { Value with } \\
\text { B3LYP/6-311++G (d,p) }\end{array}$ \\
\hline$\beta_{\mathrm{xxx}}$ & 65.14063 & $\mu_{\mathrm{x}}$ & 1.3621 \\
\hline$\beta_{\mathrm{xxy}}$ & 280.3822 & $\mu_{\mathrm{y}}$ & 1.0675 \\
\hline$\beta_{\mathrm{xyy}}$ & -37.7120 & $\mu_{\mathrm{z}}$ & 0.0000 \\
\hline$\beta_{\mathrm{yyy}}$ & -90.5951 & $\mu_{\mathrm{t}}$ & 1.7305 \\
\hline$\beta_{\mathrm{xxz}}$ & 0.0000 & $\alpha_{\mathrm{xx}}$ & 140.0498 \\
\hline$\beta_{\mathrm{xyz}}$ & 0.0000 & $\alpha_{\mathrm{xy}}$ & 0.27949 \\
\hline$\beta_{\mathrm{yyz}}$ & 0.0000 & $\alpha_{\mathrm{yy}}$ & 110.5503 \\
\hline$\beta_{\mathrm{xzz}}$ & 8.6064 & $\alpha_{\mathrm{xz}}$ & 0.0000 \\
\hline$\beta_{\mathrm{yzz}}$ & -13.2139 & $\alpha_{\mathrm{yz}}$ & 0.0000 \\
\hline$\beta_{\mathrm{zzz}}$ & 0.0000 & $\alpha_{\mathrm{zz}}$ & 52.4491 \\
\hline$\beta_{\mathrm{t}}$ & $1.556 \times 10^{-30}$ & $\alpha_{\mathrm{t}}$ & 101.0164 \\
\hline & & $\Delta \alpha$ & 1.3621
\end{tabular}

The computed dipole moment and first-order hyperpolarizability values for the chosen compound are higher than the urea value and its measure of NLO activity [1, 30-31].

\subsection{Frontier molecular orbital studies.}

Frontier molecular orbitals's (HOMO and LUMO) are essential parameters in quantum chemistry and play a vital role in the optical and electrical properties [32]. FMO's determine the way the molecule interacts with other species [33]. The energy gap between HOMO and LUMO measure the reactivity and kinetic stability $[34,-35]$ as well as the electrical conductivity [36] and optical polarizability of the molecule [37]. The energy difference between HOMO and LUMO is 0.00866 a.u. This small energy gap indicates the title compound have more reactive. With the help of HOMO and LUMO orbitals, we can compute the global reactivity parameters based on TD-DFT calculations. These parameters can be computed by the Koopman's theorem [38-42]. Parr et al. have given the idea that electrophilicity index $(\omega)$ is like chemical potential and hardness. Global reactivity descriptors such as chemical softness, hardness, chemical potential, and electrophilicity index values are obtained from Ramesh et al. [43]. The computed results of all these parameters are tabulated in Table 4. Currently, HOMO, LUMO energies, and bandgap decide the from intermolecular charge transfer (ICT) [44]. 
Table 4. Calculated energy values of dinicotinic acid.

\begin{tabular}{l|c} 
Frontier molecular orbital parameter & Value(in a.u) \\
\hline HOMO energy & -0.20958 \\
\hline LUMO energy & 0.21824 \\
\hline Frontier molecular orbital energy gap & 0.00866 \\
\hline Ionization energy $(\mathrm{I})$ & 0.20200 \\
\hline Electron affinity $(\mathrm{A})$ & 0.32404 \\
\hline Global hardness $(\eta)$ & 0.14024 \\
\hline Chemical potential $(\mu)$ & -0.35771 \\
\hline Global electrophilicity power $(\omega)$ & 0.56985
\end{tabular}

\subsection{Thermodynamic parameters and rotational constants.}

The computed results of thermodynamic parameters such as SCF energy, vibrational energy $\left(E_{v i b}\right)$, Specific heat capacity at constant volume $\left(C_{v}\right)$, entropy $(S)$, zero-point energy $\left(\mathrm{E}_{0}\right)$, and rotational constants have been performed for title molecule using DFT employing B3LYP method with the basis set of 6-311+G(d,p) and are presented in Table 5. All the present investigations were done in the gas phase, and hence they cannot be used in solution [45-46].

Table 5. Thermodynamic parameters of dinicotinic acid.

\begin{tabular}{l|l} 
Thermodynamic parameter & 35PDICA \\
\hline SCF & -625.62 \\
\hline Vibrational energy ( $\left.\mathrm{E}_{\mathrm{vib}}\right)$ & 78.476 \\
\hline $\mathrm{C}_{\mathrm{v}}$ & 36.907 \\
\hline Entropy (S) & 100.533 \\
\hline Zero-point energy ( $\left.\mathrm{E}_{0}\right)$ & 73.960 \\
\hline Rotational constants $(\mathrm{GHz})$ & \\
\hline A & 0.09157 \\
\hline B & 0.02803 \\
\hline C & 0.02146
\end{tabular}

\section{Conclusions}

The structural, spectroscopic (FT-IR, FT-Raman) and calculated (DFT \& IVP) was performed for the dinicotinic acid molecule. The calculated frequencies of dinicotinic acid using density functional theory better agree with the corresponding observed frequencies. A detailed vibrational analysis of the title molecule is performed using the density functional theory (DFT) method and solving IVP using optimized molecule geometries. The NLO parameters, HOMO, and LUMO energies were performed. The first-order hyperpolarizability $\left(\beta_{\text {tot }}\right)$ and dipole moment were also calculated for this molecule. It is found that the values of $\beta_{\text {tot }}$ and $\mu_{\mathrm{t}}$ are lower than urea and which shows that the Dinicotinic acid is an excellent NLO behavior.

\section{Funding}

This research received no external funding.

\section{Acknowledgments}

The authors are thanks to the CSIR, and SAIF, IIT-Madras for spectral measurements

\section{Conflicts of Interest}




\section{References}

1. Laxman Naik, J.; Venkatram Reddy, B.; Prabavathi, N. Experimental (FTIR and FT-Raman) and theoretical investigation of some pyridine-dicarboxylic acids. J. Mol. Struct. 2015, 1100, 43-58, https://doi.org/10.1016/j.molstruc.2015.06.064.

2. Eubank, J.F.; Walsh, R.D.; Poddar, P.; Srikanth, H.; Larsen, R.W.; Eddaoudi, M. Metal-Organic Framework Diversity via Heterocoordination of a Multifunctional Ligand: SrAl2 and a Novel $(3,4)$-Connected Network. Crystal Growth \& Design 2006, 6, 1453-1457,https://doi.org/10.1021/cg0600871.

3. Tong, M.-L.; Wang, J.; Hu, S. Synthesis, structures and magnetic properties of two 3D 3,4pyridinedicarboxylate bridged manganese(II) coordination polymers incorporating 1D helical Mn(carboxylate)2 chain or $\mathrm{Mn} 3(\mathrm{OH}) 2$ chain. J. Solid State Chem. 2005, 178, 1518-1525, https://doi.org/10.1016/j.jssc.2005.02.025.

4. Slieman Tony, A.; Nicholson Wayne, L. Role of Dipicolinic Acid in Survival ofBacillus subtilis Spores Exposed to Artificial and Solar UV Radiation. Appl. Environ. Microbiol. 2001, 67, 12741279,https://doi.org/10.1128/AEM.67.3.1274-1279.2001.

5. Wasylina, L.; Kucharska, E.; Weglinski, Z.; Puszko, A. The13C NMR, UV and IR absorption spectra of pyridinedicarboxylic acids. Chemistry of Heterocyclic Compounds 1999, 35, 186-194, https://doi.org/10.1007/BF02251707.

6. Kose, E.; Bardak, F.; Atac, A.; Karabacak, M.; Cipiloglu, M.A. Determination of structural and vibrational spectroscopic features of neutral and anion forms of dinicotinic acid by using NMR, infrared and Raman experimental methods combined with DFT and HF. Spectrochimica Acta Part A: Molecular and Biomolecular Spectroscopy 2013, 114, 38-45, https://doi.org/10.1016/j.saa.2013.05.049.

7. Frisch, M.J.; Trucks, G.W.; Schlegel, H.B.; Scuseria, G.E.; Robb, M.A.; Cheeseman, J.R.; Scalmani, G.; Barone, V.; Mennucci, B.; Petersson, G.A. Gaussian, Inc., Wallingford CT. Gaussian 092009.

8. Becke, A.D. A new mixing of Hartree-Fock and local density-functional theories. The Journal of Chemical Physics 1993, 98, 1372-1377,https://doi.org/10.1063/1.464304.

9. Lee, C.; Yang, W.; Parr, R.G. Development of the Colle-Salvetti correlation-energy formula into a functional of the electron density. Physical Review B 1988, 37, 785-789, https://doi.org/10.1103/PhysRevB.37.785.

10. Wilson, E.B. The Normal Modes and Frequencies of Vibration of the Regular Plane Hexagon Model of the Benzene Molecule. Phys. Rev. 1934, 45, 706-714, https://doi.org/10.1103/PhysRev.45.706.

11. Varsányi, G. Assignments for vibrational spectra of seven hundred benzene derivatives; John Wiley \& Sons: 1974; Vol. 1.

12. Koczoń, P.; Dobrowolski, J.C.; Lewandowski, W.; Mazurek, A.P. Experimental and theoretical IR and Raman spectra of picolinic, nicotinic and isonicotinic acids. J. Mol. Struct. 2003, 655, 89-95, https://doi.org/10.1016/S0022-2860(03)00247-3.

13. John, N.L.; Abraham, S.; Sajan, D.; Sarojini, B.K.; Narayana, B. Quantum chemical studies of molecular structure, vibrational spectra and non-linear optical properties of p-iodoaniline and p-bromoaniline. J. Mol. Struct. 2020, 1222, 128939,https://doi.org/10.1016/j.molstruc.2020.128939.

14. Karabacak, M.; Kurt, M. The spectroscopic (FT-IR and FT-Raman) and theoretical studies of 5-bromosalicylic acid. J. Mol. Struct. 2009, 919, 215-222,https://doi.org/10.1016/j.molstruc.2008.09.012.

15. Lin-Vien, D.; Colthup, N.B.; Fateley, W.G.; Grasselli, J.G. The handbook of infrared and Raman characteristic frequencies of organic molecules; Elsevier: 1991.

16. Silverstein, M.; Claytron Basseler, G.; Morill, C. Spectrometric Identification of Organic compounds, Jhon Wiley and sons, New York, 1981, volume 39, 1962/546-552. ISBN: 978-0-470-61637-6.

17. Sundaraganesan, N.; Ilakiamani, S.; Dominic Joshua, B. FT-Raman and FT-IR spectra, ab initio and density functional studies of 2-amino-4,5-difluorobenzoic acid. Spectrochimica Acta Part A: Molecular and Biomolecular Spectroscopy 2007, 67, 287-297, https://doi.org/10.1016/j.saa.2006.07.016.

18. McCann, K.; Laane, J. Raman and infrared spectra and theoretical calculations of dipicolinic acid, dinicotinic acid, and their dianions. J. Mol. Struct. 2008, 890, 346-358, https://doi.org/10.1016/j.molstruc.2008.05.046.

19 Kourat, O.; Djafri, A.; Benhalima, N.; Megrouss, Y.; Belkafouf, N.E.H.; Rahmani, R.; Daran, J.-C.; Djafri, A.; Chouaih, A. Synthesis, crystal structure, Hirshfeld surface analysis, spectral characterization, reduced density gradient and non-linear optical investigation on (E)-N'-(4-nitrobenzylidene)-2-(quinolin-8-yloxy) acetohydrazide monohydrate: A combined experimental and DFT approach. J. Mol. Struct. 2020, 1222, 128952,https://doi.org/10.1016/j.molstruc.2020.128952.

20. Nivetha, K.; Aravinth, K.; Senthil, K.; Kalainathan, S. Evaluation of structural, spectral, thermal and optical 
properties of an efficient centrosymmetric organic single crystal 2-[2-(4-diethylamino-phenyl)-vinyl]-1methyl pyridinium tetrafluoroborate for non-linear optical applications. J. Mol. Struct. 2021, 1225, 129082,https://doi.org/10.1016/j.molstruc.2020.129082.

21. Venkata Ramana Rao, P.;Srishilam, K.;Ramesh, G.;Venkatram Reddy, B.;Ramana Rao,G. NMR \& Electronic Spectra, NLO, FMO, NBO and Thermodynamic Properties of Pentachlorophenol: An Experimental and Theoretical Investigation.Asian J. Chem. 2020,32, 3057-3062,https://doi.org/10.14233/ajchem.2020.22945.

22. Pekparlak, A.; Tamer, Ö.; Kanmazalp, S.D.; Berber, N.; Arslan, M.; Avcı, D.; Dege, N.; Tarcan, E.; Atalay, Y. Synthesis, crystal structure, spectroscopic (FT-IR, 1H and 13C NMR) and non-linear optical properties of a novel potential HIV-1 protease inhibitor. Chem. Phys. Lett. 2020, 742, 137171, https://doi.org/10.1016/j.cplett.2020.137171.

23. Ramesh, G.; Prashanth, J.; Laxman Naik, J.; Venkatram Reddy, B. Molecular Structure, Vibrational Analysis, Hyperpolarizability and NBO Analysis of 3-Methyl-Picolinic Acid Using SQM Calculations. J. Struct. Chem. 2018, 59, 1022-1031, https://doi.org/10.1134/S0022476618050037.

24. Srishailam, K.; Ramaiah, K.; Reddy, K.L.; Reddy, B.V.; Rao, G.R. Synthesis and evaluation of molecular structure from torsional scans, study of molecular characteristics using spectroscopic and DFT methods of some thiosemicarbazones, and investigation of their anticancer activity. Chemical Papers 2021, 75, 36353647,https://doi.org/10.1007/s11696-021-10595-x.

25. Kumar, A.;Mishra, A. Computational Design, Spectral, NBO, DOS, Bioactivity Evaluation, ADMET Analysis, Third-Order non-linear Optical and Quantum Chemical Investigations on Hydrogen Bonded Novel Organic Molecular Complex of 4-[Bis[2-(acetyloxy)ethyl]amino]benzaldehyde (4B2AEAB) Derivatives for Opto-Electronic Applications. Asian J. $\quad$ Chem.2020, 2793 2820,https://doi.org/10.14233/ajchem.2020.22838.

26. Geskin, V.M.; Lambert, C.; Brédas, J.-L. Origin of High Second- and Third-Order Nonlinear Optical Response in Ammonio/BoratoDiphenylpolyene Zwitterions: the Remarkable Role of Polarized Aromatic Groups. J. Am. Chem. Soc. 2003, 125, 15651-15658,https://doi.org/10.1021/ja035862p.

27. Nakano, M.; Fujita, H.; Takahata, M.; Yamaguchi, K. Theoretical Study on Second Hyperpolarizabilities of Phenylacetylene Dendrimer: Toward an Understanding of Structure-Property Relation in NLO Responses of Fractal Antenna Dendrimers. J. Am. Chem. Soc. 2002, 124, 9648-9655, https://doi.org/10.1021/ja0115969.

28. Sajan, D.; Joe, H.; Jayakumar, V.S.; Zaleski, J. Structural and electronic contributions to hyperpolarizability in methyl p-hydroxy benzoate. J. Mol. Struct. 2006, 785, 43-53, https://doi.org/10.1016/j.molstruc.2005.09.041.

29. Sun, Y.-X.; Hao, Q.-L.; Wei, W.-X.; Yu, Z.-X.; Lu, L.-D.; Wang, X.; Wang, Y.-S. Experimental and density functional studies on 4-(3,4-dihydroxybenzylideneamino)antipyrine, and 4-(2,3,4trihydroxybenzylideneamino)antipyrine. Journal of Molecular Structure: THEOCHEM 2009, 904, 7482,https://doi.org/10.1016/j.theochem.2009.02.036.

30. Prabavathi, N.; Senthil Nayaki, N.; Venkatram Reddy, B. Molecular structure, vibrational spectra, natural bond orbital and thermodynamic analysis of 3,6-dichloro-4-methylpyridazine and 3,6-dichloropyridazine-4-carboxylic acid by dft approach. Spectrochimica Acta Part A: Molecular and Biomolecular Spectroscopy 2015, 136, 1134 1148,https://doi.org/10.1016/j.saa.2014.09.137.

31. Choudhary, N.; Bee, S.; Gupta, A.; Tandon, P. Comparative vibrational spectroscopic studies, HOMO-LUMO and NBO analysis of N-(phenyl)-2,2-dichloroacetamide, N-(2-chloro phenyl)-2,2-dichloroacetamide and N(4-chloro phenyl)-2,2-dichloroacetamide based on density functional theory. Computational and Theoretical Chemistry 2013, 1016, 8-21,https://doi.org/10.1016/j.comptc.2013.04.008.

32. Arı, H.; Özpozan, T.; Kabacalı, Y.; Saçmac1, M. Monomeric or dimeric? A theoretical and vibrational spectroscopic approach to the structural stability of 5-(4-metoxy benzoyl)-6-(4-metoxyphenyl)-3-methyl-2thioxo-2,3-dihydropyrimidine-4(1H)-on. $\quad J . \quad$ Mol. $\quad$ Struct. $\quad \mathbf{2 0 2 0 ,} \quad$ 1222, 128848,https://doi.org/10.1016/j.molstruc.2020.128848.

33 Robert, H.M.; Usha, D.; Amalanathan, M.; Geetha, R.R.J.; Mary, M.S.M. Vibrational spectral, density functional theory and molecular docking analysis on 4-nitrobenzohydrazide. J. Mol. Struct. 2021, 1223, 128948,https://doi.org/10.1016/j.m.2020molstruc.2020.128948.

34. Govindammal, M.; Prasath, M.; Kamaraj, S.; Muthu, S.; Selvapandiyan, M. Exploring the molecular structure, vibrational spectroscopic, quantum chemical calculation and molecular docking studies of curcumin: A potential PI3K/AKT uptake inhibitor. Heliyon 2021, 7, e06646,https://doi.org/10.1016/j.heliyon.2021.e06646.

35. Ravindranath, L.; Reddy, B.V. Theoretical and experimental study of torsional potentials, molecular structure (monomer and dimer), vibrational analysis and molecular characteristics of some dimethyl bipyridines. $J$. 
Mol. Struct. 2020, 1200, 127089, https://doi.org/10.1016/j.molstruc.2019.127089.

36 Vidhya, V.; Austine, A.; Arivazhagan, M. Experimental approach, theoretical investigation and molecular docking of 2-chloro-5-fluoro phenol antibacterial compound. Heliyon 2020, 6 , e05464,https://doi.org/10.1016/j.heliyon.2020.e05464.

37. Akram, N.; Mansha, A.; Premkumar, R.; Franklin Benial, A.M.; Asim, S.; Iqbal, S.Z.; Ali, H.S. Spectroscopic, quantum chemical and molecular docking studies on 2, 4-dimethoxy-1, 3, 5-triazine: a potent inhibitor of protein kinase CK2 for the development of breast cancer drug. Mol. Simul. 2020, 46, 13401353,https://doi.org/10.1080/08927022.2020.1822526.

38. Koopmans, T. Über die Zuordnung von Wellenfunktionen und Eigenwertenzu den EinzelnenElektronenEines Atoms. Physica1934, 1, 104-113,https://doi.org/10.1016/S0031-8914(34)90011-2.

39. Parr, R.G.; Szentpály, L.v.; Liu, S. Electrophilicity Index. J. Am. Chem. Soc. 1999, 121, 19221924,https://doi.org/10.1021/ja983494x.

40. Chidan Kumar, C.S.; Yohannan Panicker, C.; Fun, H.-K.; Sheena Mary, Y.; Harikumar, B.; Chandraju, S.; Quah, C.K.; Ooi, C.W. Molecular structure, FT-IR, first order hyperpolarizability, NBO analysis, HOMO and LUMO analysis of 2-(4-chlorophenyl)-2-oxoethyl 3-methylbenzoate by HF and density functional methods. Spectrochimica Acta Part A: Molecular and Biomolecular Spectroscopy 2014, 128, 327336,https://doi.org/10.1016/j.saa.2014.02.185.

41. Fleming, I. Frontier Orbitals and Organic Chemical Reactions, John Wiley and Sons, New York, 1976.

42. Aihara, J.-i. Reduced HOMO-LUMO Gap as an Index of Kinetic Stability for Polycyclic Aromatic Hydrocarbons. The Journal of Physical Chemistry A 1999, 103, 74877495,https://doi.org/10.1021/jp990092i.

43. Ramesh, G.; Reddy, B.V. Spectroscopic investigation on structure (monomer and dimer), molecular characteristics and comparative study on vibrational analysis of picolinic and isonicotinic acids using experimental and theoretical (DFT \& IVP) methods. J. Mol. Struct. 2018, 1160, 271292,https://doi.org/10.1016/j.molstruc.2018.01.083.

44. Senthilkumar, K.;Naina Mohammed, S.S.;Kalaiselvan, S. Free Radical Scavenging Activity of Dihydrocaffeic Acid: A Quantum Chemical Approach. Asian J. of Chem.2021,33, 937944,https://doi.org/10.14233/ajchem.2021.23068.

45. Muthu, S.; IsacPaulraj, E. Spectroscopic and molecular structure (monomeric and dimeric structure) investigation of 2-[(2-hydroxyphenyl) carbonyloxy] benzoic acid by DFT method: A combined experimental and theoretical study. J. Mol. Struct. 2013, 1038, 145-162,https://doi.org/10.1016/j.molstruc.2013.01.043.

46. Chandralekha, B.; Hemamalini, R.; Muthu, S.; Sevvanthi, S. Spectroscopic (FT-IR, FT-RAMAN, NMR, UVVis) investigations, computational analysis and molecular docking study of 5-bromo-2-hydroxy pyrimidine. J. Mol. Struct. 2020, 1218, 128494, https://doi.org/10.1016/j.molstruc.2020.128494. 